\title{
A formação da identidade do aluno na educação a distância: reflexões para um debate
}

\section{The distance learning student's identity formation: reflections for a debate}

\author{
Cristina Azra Barrenechea*
}

\begin{abstract}
RESUMO
Este artigo procurou levantar algumas reflexões a respeito do processo de formação da identidade e da autonomia do aluno do curso de graduação "Formação de professores das séries iniciais do ensino fundamental na modalidade a distância" na UFPR. Sendo esta uma modalidade nova dentro da universidade, este processo oferece uma série de experiências de recriação da identidade não só de alunos, mas de professores e funcionários envolvidos no projeto. As experiências deste curso vêm renovando concepções e práticas pedagógicas para uma modalidade ainda pouco vivenciada no Brasil.

Palavras-chave: educação a distância, autonomia, identidade, aluno da educação a distância.
\end{abstract}

\begin{abstract}
This article intends to raise some reflexions about the formation process of student's autonomy and identity on a distance education undergraduate course in the field of Pedagogy with major in fundamental education at Federal University of Parana, Brazil. Because this is a new modality of education within university, this process offers a series of experiences on

* Professor Assistente do Depto. de Planejamento e Administração Escolar da Universidade Federal do Paraná, membro do Núcleo de Educação a Distância NEAD/UFPR, Mestre em Tecnologia Educacional e Ecologia da Mídia (NYU, U.S.A.). E-mail: cristinab2001@yahoo.com.br
\end{abstract}


the identity recriation, not only for students, as well as to professors and other professionals involved in this project. The experiences in this course are renewing the pedagogical practices and conceptions in a educational modality which is still new in Brazil.

Key-words: long distance education, autonomy, identity, learner.

A demanda por capacitação em nível de graduação originada pela lei 9.394/96 que determina que os professores em exercício tenham curso de graduação em pedagogia ou licenciatura, vem causando uma crescente preocupação para as instituições de ensino. Com a falta de estrutura e recursos das instituições públicas de ensino superior para atender este público emergente, tornou-se cada vez mais evidente a necessidade de soluções alternativas e inovadoras de capacitação. A EAD tem se firmado como modalidade educacional nas últimas décadas em diversos países do mundo. O Paraná tinha em torno de 30.000 professores sem graduação em 1999 e a oferta de vagas disponível pelas instituições estaduais e privadas atenderia apenas a uma pequena parcela destes professores. Dessa forma, a necessidade pela oferta de cursos na modalidade de Educação a Distância que atendessem a essa demanda desenhou-se de forma mais contundente e deu início, em julho de 2000, ao curso de Pedagogia Séries Iniciais do Ensino Fundamental na modalidade de Educação a Distância ofertado pelo Setor de Educação em parceria com o Núcleo de Educação a Distância da UFPR.

Este projeto, pioneiro no Paraná e na região Sul e Sudeste enfrenta um cenário muitas vezes desanimador pela falta de uma política governamental e institucional que dê suporte tanto no aspecto de seu financiamento quanto no aspecto político. Seu desenvolvimento propõe interessantes alternativas e perspectivas para os professores, alunos e tutores, mas também intensos desafios. A EAD tem se mostrado um dos patamares para a expansão das oportunidades de acesso à educação superior em nosso país, apresentando propostas de qualidade e excelência pedagógica, e afirmando-se como campo epistemológico de estudos inovadores.

Neste artigo, pretende-se enfocar as mudanças ocorridas no cotidiano dos alunos da EAD ao ingressarem no curso de graduação "Formação de Professores - Séries Iniciais do Ensino Fundamental na modalidade a distância". Estas mudanças são amplas pois envolvem os alunos em situações acadêmicas antes desconhecidas. $\mathrm{O}$ espaço acadêmico destes alunos não é somente o Centro no qual se encontram periodicamente nos momentos presenciais do curso, mas em casa, na escola, no grupo de trabalho em suas cidades e na própria Universidade Federal do Paraná. Este espaço que, embora distante 
fisicamente, está presente no imaginário como aglutinador da sua identidade de aluno. A seguir serão apresentados alguns fatos que marcaram as experiências dos alunos com a UFPR enquanto instituição.

No ano de 2001 uma aluna deste Curso do Centro Associado de Maringá veio visitar a UFPR e apresentou-se à Biblioteca como aluna do Curso a Distância pedindo para tirar uma carteirinha. Ela queria emprestar um livro. Isso não foi possível porque afirmaram que os alunos deste curso não tinham permissão para pertencer ao sistema de empréstimo. Por ter certeza de que esse era um direito de todos os alunos da UFPR, ela procurou a pessoa responsável na biblioteca. Descobriu então que a política para os alunos da EAD era diferenciada, e a justificativa dada era de que o aluno a distância atrasaria ou não devolveria os livros. Bastante constrangida com a negativa pública, a aluna foi ajudada por um dos professores do Setor de Educação que prontamente emprestou o livro para que ela xerocasse a parte desejada. A pergunta que fica é: se o aluno atrasa ou não devolve o livro, este é um problema do aluno ou da biblioteca? Caso qualquer aluno matriculado na UFPR não devolva um livro, ele será impedido de emprestar outros, e só poderá se formar se não estiver em dívida com a instituição. Se esta política funciona com os alunos da presencial, por que não funcionaria com os alunos da graduação a distância?

Naquele ano, outra aluna da mesma turma de Maringá obteve sua carteirinha da biblioteca justamente por não ter se identificado como aluna do curso de graduação a distância. Ela apresentou apenas seu comprovante de matrícula do DAA, igual ao de todos os alunos da UFPR. Por não suspeitarem de suas credenciais "ilegítimas" concederam pleno acesso ao ambicionado acervo.

Este procedimento da biblioteca reflete uma atitude arbitrária por não estar sustentada em nenhuma regulamentação específica. $\mathrm{O}$ fato dos Centros Associados estarem localizados em outras cidades justificaria o nãopertencimento dos alunos da EAD ao sistema de bibliotecas? Este procedimento, que parece a nós equivocado, pode estar apoiado numa percepção de transitoriedade do curso, ou seja, de que ele existe apenas atender a uma demanda emergencial criada pela LDB. Esta transitoriedade estaria fundamentando uma ausência de política institucional para estes alunos, justificando assim o descomprometimento com uma política específica para a EAD na instituição? Afinal, de outra forma, poderia haver outras soluções para a disponibilização dos serviços da UFPR para os alunos nos Centros Associados. Por exemplo, o uso de malotes para empréstimos de livros por meio da biblioteca dos Centros Associados e destes para com as bibliotecas sediadas nos vários campi, já que este sistema de empréstimo ocorre inter-universidades. 
Esta atitude sugere uma percepção política equivocada de alguns dos nossos órgãos em relação aos direitos e legitimidade do aluno da graduação a distância. Sem sabermos se o curso de graduação será transitório ou não, apenas podemos afirmar que seus alunos estão efetivamente matriculados e isto justifica seu pleno atendimento.

Na regulamentação institucional não há nenhuma diferença entre os alunos dos cursos na modalidade a distância e os alunos da presencial. Isto nos leva a um outro drama, muito mais severo, que fere princípios e valores fundamentais na nossa sociedade: o direito ao voto. Esta situação ocorreu durante o processo de eleição para representantes a reitor e vice-reitor, e a diretor do Setor de Educação, no qual o curso de pedagogia a distância está vinculado.

Aos alunos do curso de graduação a distância, que constituem um universo de 800 estudantes, não foi permitida a participação nas eleições. A discussão sobre o direito ao voto e à participação na eleição de seus representantes foi postergada para 2003. A alegação dos Conselhos é de que não havia nenhuma regulamentação ou normatização existente que permitisse aos alunos o direito ao voto. Por outro lado, podemos afirmar que certamente não existia nenhuma regulamentação que os impedisse de votar. Os Conselhos decidiram que este assunto teria que ser pautado para aprovação a fim de criar jurisprudência. Fica aqui a pergunta: não ferindo a nenhuma regulamentação vigente, a negação do direito ao voto não viria a ferir um direito estabelecido em uma instância superior, a Constituição brasileira, e, por consequiência, a democracia?

Se os alunos fazem parte do corpo discente, não seriam eles que deveriam legitimar-se como partícipes deste processo, exercendo seu dever e direito de voto? Por que novamente alguém externo deve decidir quais serão os direitos de um grupo diferenciado?

Trata-se de uma ideologia que várias organizações lutam para superar, a idéia de que as diferenças justificam os privilégios de uns sobre os outros. Assim como a mulher, o pobre, o negro, o homossexual, este aluno está ocupando um lugar periférico em relação aos outros integrantes do coletivo. Ou seja, um aluno que tem matrícula, estuda e se formará sob a insígnia da UFPR está sendo tratado como não-aluno devido à uma crença equivocada.

Para CASTORIADIS (2000) a lei arbitrária do outro se opõe à autonomia do sujeito. Esta relação de dominação é, para o aluno, uma negação dos seus direitos e da sua identidade; e para aquele que domina, seu lugar é legitimado ainda mais pela arbitrariedade. Se fosse uma lei regulamentada, o aluno saberia definir contra qual obstáculo ele deveria lutar para conquistar seus direi- 
tos. Mas sendo um procedimento arbitrário, é construído culturalmente, é um código não verbal de conduta. Situando-se neste espaço ambíguo do subjetivo, o aluno se vê diante de um vácuo onde não encontra eco para suas demandas. Ele não tem um fórum para discutir estas questões. Ele não tem um Centro Acadêmico que o represente.

Enquanto ele não se constitui como sujeito coletivo na universidade, ele não consegue construir sua autonomia. Pois para se ter autonomia é preciso que haja um sujeito desta autonomia. Se ele não é visto como sujeito participante nesta comunidade, ele não se percebe como sujeito integrante deste coletivo, para então buscar sua representação e legitimação. Este sujeito se baseia em um identidade coletiva de aluno da UFPR.

Isto não significa que sua autonomia está comprometida enquanto sujeito individual. Esta está sendo construída ao longo de suas experiências nas relações sociais. Mas a autonomia enquanto aluno da UFPR parece algo muito abstrato, pois fica a pergunta: "O que é ser aluno da UFPR?" Existem regras próprias da instituição que todos devemos respeitar para nos guiar, regras estabelecidas, baseadas em valores e princípios. Mas o procedimento da biblioteca, que mais parece uma política de empréstimo, toma a aparência de norma, apesar de não haver uma normatização que regule a EAD nesta universidade. $\mathrm{O}$ aluno da EAD percebe a ambigüidade e é chamado para reagir a esta e a outras regras que podem ser prejudiciais para o próprio avanço da universidade.

O resultado das eleições veio a impactar diretamente no Curso, uma vez que os representantes eleitos ainda não apresentaram uma proposta política institucional que priorize as necessidades do Curso de graduação a distância.

Se os alunos não podem votar, como eles podem ser representados? E se eles não são representados, como eles poderão ser reconhecidos como sujeitos-alunos e ter seus direitos defendidos?

Um segundo fato, ligado aos alunos da UFPR, vem acrescentar mais um elemento a esta discussão. Suas implicações políticas e simbólicas nos levam a considerá-lo como de fundamental importância para entender como está se dando a inserção do Curso de Pedagogia a distância na UFPR.

Os alunos do curso na modalidade a distância não formaram ainda um Centro Acadêmico que os represente. Apesar de terem eleito um representante para participar das reuniões do Colegiado do Curso, os alunos não têm uma entidade representativa.

O Centro Acadêmico (CAAT) deve representar só os alunos da pedagogia presencial ou também os da pedagogia a distância? Se ele representa também os alunos a distância, estes não deveriam participar da votação da chapa para 
o CAAT? E mesmo compor uma chapa com alunos das duas modalidades? Se ele não representa, então os alunos da pedagogia a distância deveriam formar seu próprio Centro Acadêmico.

Esta indefinição acarreta uma dificuldade para defender seus interesses dentro da universidade. E um destes interesses é o acesso à carteirinha de estudante da UNE (União Nacional Estudantil).

O Centro Acadêmico está instituído para representar os estudantes de cada curso da UFPR. Ao Centro Acadêmico da Pedagogia foi encaminhado o pedido de carteirinha de estudante para os alunos da graduação a distância pelo coordenador do curso em 2001. Apesar de pautado para deliberação, esta demanda feita pela coordenação do curso ainda não obteve resposta. Coube ao CAAT a deliberação da carteirinha de estudante aos alunos do Curso a distância.

O que esta situação nos sugere? Ao mesmo tempo que não podemos afirmar que exista uma resistência por parte do CAAT e/ou dos alunos da pedagogia presencial também não podemos afirmar que há receptividade. Isto com certeza reflete uma ausência de política de aproximação entre os alunos das duas modalidades.

A carteirinha de estudante e da biblioteca são documentos que identificam o aluno também simbolicamente. A identidade coletiva é marcada por signos que representam os valores compartilhados pelo coletivo e reconhecidos como unificadores. Eles constroem símbolos que estão baseados em crenças de valor, assim como usam e reconhecem no emblema da UFPR um signo em comum.

A história e os valores transmitidos pelo coletivo da UFPR fornecem a matéria-prima que possibilita aos alunos construírem novas identidades e códigos culturais em meio aos novos modelos de relação. Estes modelos de relação são multifacetados, nos quais eles vivenciam, por um lado espaços democráticos, e por outro lado processos de dominação. Processos estes que estão nos fluxos de informação, nas não-regulamentações, no pouco incentivo da instituição para estreitar as relações entre os alunos do curso presencial com os alunos da modalidade a distância. Para construírem sua própria história, eles registram e trocam experiências, restabelecendo a comunicação por meio das histórias que são contadas e dos valores que são compartilhados no grupo.

Os alunos passam a construir suas identidades a partir dos elementos formadores de dados pela instituição, pelos professores, pelos colegas e por todos aqueles que nomeiam e qualificam sua prática discente. Estes conteúdos formam uma base de suporte para a constituição de sua identidade de aluno. 
Os valores que a instituição investe nos alunos são assimilados, por vezes enquanto verdades, outras vezes com estranheza. Mas em nenhum momento com indiferença, pois eles se encontram em processo de consolidação de sua identidade de grupo em um curso pioneiro na universidade.

Ao terem acesso negado na biblioteca buscam entender a lógica da instituição. Existe uma reivindicação crescente entre os alunos para que tenham seus direitos assegurados. Mas ainda persiste a esperança de que os direitos sejam legitimados por uma iniciativa da instituição. Não há uma lógica única na instituição, e estas lógicas convivem nas relações sociais muitas vezes gerando contradições e conflitos.

Para Gilberto Velho ${ }^{1}$ uma das principais características das sociedades complexas é o fato dela ter vários estilos de vida e visões de mundo convivendo ao mesmo tempo, ou seja, a convivência de várias racionalidades em um mesmo espaço. Os indivíduos podem transitar por vários domínios e variar o seu grau de adesão. Dessa forma, "na sociedade complexa, particularmente, a coexistência de diferentes mundos constitui a sua própria dinâmica" (VELHO, 1994, p. 27).

O pensamento crítico desenvolvido neste ambiente de estudos e pesquisa vivenciado pelos grupos nos Centros Associados está formando nos alunos uma posição, não de passividade, mas de transformação de idéias, conceitos e valores. E é esta posição crítica que os ajuda a questionar os valores e práticas da sociedade, e dá suporte para que questionem valores e práticas da universidade em relação a eles.

Existem grandes contradições entre o que se imagina sobre a educação a distância e a experiência concreta do Curso de Pedagogia na modalidade de EAD. E é devido a estas diferenças, entre o real e o imaginado, que tem-se a impressão de que estamos falando de duas ou mais formas de educação a distância completamente diferentes, algumas delas frutos da representação destas diferentes lógicas que convivem na instituição. Certamente isto dificulta o diálogo, pois os integrantes do Curso a distância vivenciam uma experiência que não comprova as verdades que muitas destas lógicas defendem, como por exemplo: que a EAD é uma educação sem qualidade e aligeirada, que ela é mercantilista com perspectivas lucrativas, com uma concepção tecnicista, que é a favor das políticas neo-liberais que contribuem para o desmonte da universidade etc. Isto pode até se aplicar a outros modelos de edu-

1 velHo, G. Projeto e metamorfose: antropologia das sociedades complexas. Rio de Janeiro: Zahar, 1994. 
cação a distância, como também a outros modelos de educação presencial. Mas é preciso dar a conhecer o modelo de EAD da UFPR, que por enquanto não encontrou um fórum dentro da universidade para que esta discussão seja promovida, e assim muitos pontos do projeto pedagógico e sua prática possam ser esclarecidos. Este modelo já foi estudado pela Unesco, pelo Pólo de avaliação da UniRede e até na França, pois se constitui em referencial de excelência para outros cursos se pautarem. Esperamos que estas dificuldades no diálogo sobre a EAD sejam sanadas à medida que o projeto se torne conhecido.

Se os sujeitos protagonistas desta nova experiência vêem em si próprios um sentido que não é o seu, que é projetado pelo outro, seja por desconhecimento ou má-fé, a comunicação provavelmente tornar-se-á impossível. Desde o início deste projeto existiu uma tensão constante entre aqueles que acreditavam na EAD e os que criticavam a EAD.

Estas contradições, se não tiverem um espaço de reconhecimento para os novos sujeitos, podem gerar sintomas na instituição, como grupos de controle do poder e grupos de resistência a este poder castrador. Assim como os movimentos sociais que buscam reconhecimento de suas necessidades no espaço político brasileiro, os grupos marginalizados na academia unem-se para lutar pelo reconhecimento de seus direitos. Apesar de acreditarmos que o diálogo é o melhor caminho, ele só é possível se há por parte do coletivo um reconhecimento de suas identidades, seus desejos e crenças e sem a exclusão de grupos politicamente periféricos na instituição.

Depois de três anos vivenciando um curso na modalidade a distância, estamos preparados para discuti-lo e avaliá-lo, e principalmente, para defendêlo. E se nos derem oportunidade, para ampliá-lo. Será necessário um diálogo aberto dentro da instituição para que os caminhos e os protagonistas que estão se construindo sejam reconhecidos pela comunidade acadêmica.

Sabemos que é importante ter em mente o projeto original, o Projeto Político Pedagógico do Curso aprovado pelo CEPE, para que as premissas iniciais garantam a qualidade do curso. Mas nós temos transformado sentidos em ações na busca de objetivos que não são só aqueles iniciais do projeto, mas novos objetivos, traçados principalmente nas relações entre os protagonistas. Que são: a busca de continuidade do curso como política de inclusão e democratização dos saberes produzidos na UFPR, ampliação das oportunidades de formação profissional, ampliação da pesquisa em uma área nova e promissora e a inserção da educação a distância na instituição.

A prática docente junto a estes alunos tem transformado o sentido da prática pedagógica para muitos professores, principalmente para aqueles que 
se envolveram na institucionalização do Curso. Pois, o fato dele não estar institucionalizado como os da modalidade presencial, requer uma maior participação dos professores, no fazer e criar de uma prática pedagógica inédita e inovadora.

A imprevisibilidade nas relações, entre estes protagonistas, formaram laços que marcaram e estruturaram relações indestrutíveis, de verdadeiras trocas de conhecimentos, vivências, afetos e valores. Trocas fundamentais para a constituição de relações de confiança. E são estas relações de confiança que dão suporte à discussão acadêmica e ao respeito pelas divergências teóricas, políticas e religiosas. Acima da uniformidade de pensamento, buscou-se construir relações de respeito entre os protagonistas do curso. Este projeto não é visto pelos que o fazem como algo transitório, uma medida para responder a uma demanda emergencial por formação, é vivido como uma oportunidade de concretizar um ideal de educação e de autonomia: a democratização do ensino de qualidade.

Uma breve descrição da autonomia que nos parece relevante nesta discussão é oferecida por PRETI (2000):

Em sua etimologia, autonomia vem do grego, resultado da composição do pronome reflexivo, com posição atributiva, autos (próprio, a si mesmo) com o substantivo nomos ( lei, norma, regra). Para os gregos, significava a capacidade de cada cidade se autogovernar, de elaborar seus preceitos, suas leis, dos cidadãos decidirem o que fazer. Era o pleno direito à liberdade política e econômica. Cada cidade um Estado, um Estado democrático. Por outro lado, significava a recusa à subjugação a um rei, a um tirano, a grupos oligárquicos e a afirmação do ser cidadão e a negação do ser escravo. Era a qualidade inerente ao ser cidadão ${ }^{2}$. [...] Sabemos, porém, a luta que se trava nos bastidores para ser exercida. Há resistências, pois a autonomia representa perda para quem está no poder, para quem se coloca no outro lado da relação como detentor do saber e das decisões a serem tomadas.

2 Não esqueçamos que na Grécia clássica, a categoria "cidadão" era restrita a uma parcela reduzida da sociedade, pois dela estavam excluídos os escravos, os libertos, os estrangeiros e as mulheres." (PRETI, 2000). 
Para CASTORIADIS (2000, p. 130) "O problema da autonomia é que o sujeito encontra em si próprio um sentido que não é o seu, e que tem que transformá-lo utilizando-o; se a autonomia é essa relação na qual os outros estão sempre presentes como alteridade e como ipseidade do sujeito - então a autonomia só é concebível, já filosoficamente, como um problema e uma relação social".

No processo de inserção do curso na instituição, o aluno acaba precisando conquistar a sua autonomia diante da instituição e diante da sociedade. Esta defesa só é possível coletivamente, quando todos os sujeitos reconhecem entre si um discurso comum que é a busca da defesa de seus direitos e do reconhecimento do seu esforço pela qualidade do ensino.

Algumas vezes o discurso do outro invade a própria percepção que ele tem de si mesmo e de seus direitos. Como o discurso da pessoa responsável pela biblioteca invadiu a própria percepção que a aluna tinha de si, que ela deveria ser reconhecida como uma aluna da universidade. Para o sujeito autônomo, o discurso do outro é interiorizado para ser transformado e seu sentido é utilizado para transformar a realidade externa. Esta tensão pode ser pensada como uma tensão entre o que está instituído na UFPR e as forças instituintes de novas mudanças, necessárias para o desenvolvimento da UFPR enquanto instituição autônoma e criadora de conhecimentos e espaços democráticos.

Para CASTORIADIS o social é:

uma estrutura definida e ao mesmo tempo mutante, uma articulação objetivável de categorias de indivíduos e o que para além de todas as articulações mantém sua unidade [...] [o social é] o que só pode apresentar-se na e pela instituição, mas é sempre infinitamente mais do que a instituição, posto que é, paradoxalmente, ao mesmo tempo, o que preenche a instituição, o que se deixa formar por ela, o que sobredetermina constantemente seu funcionamento e aquilo que, em última análise a fundamenta, a cria, a mantém em existência, a altera, a destrói. Há o social instituído, mas este pressupõe sempre o social instituinte. (2000, p. 135)

O projeto revolucionário atualmente, de acordo com Castoriadis, é um projeto que deve defender a autonomia do sujeito. A sociedade que virá depois dessa luta por autonomia será tão diferente desta que nos parece uma sociedade impensada. Essa luta coloca um tensão entre a sociedade instituída 
e a sociedade instituinte que está por vir. O sujeito utiliza o que está instituído para transformar e não simplesmente assume a fala e os valores sociais do outro, que está no centro, como verdade estabelecida.

As comunidades encontram atualmente os mais variados espaços para se formar, "as pessoas resistem ao processo de individualização e atomização, tendendo a agrupar-se em organizações comunitárias que, ao longo do tempo, geram um sentimento de pertença e, em última análise, em muitos casos, uma identidade cultural, comunal" (CASTELLS, 2000, p. 79). Mas para isso é necessário que a mobilização social se dê por meio de um projeto coletivo no qual sejam defendidos interesses comuns, e a vida possa ser compartilhada e os significados produzidos.

Neste movimento de construção todos os protagonistas são responsáveis pelo projeto. O Curso de Pedagogia é um catalizador de mudanças nas comunidades onde se insere, cada movimento seu produz resultados diferentes e só a sua presença já produz algum significado para os envolvidos e para a comunidade, para o presente e para a memória coletiva desta comunidade.

A produção destes significados é essencial para a cidade, as escolas e seus protagonistas, pois marca na história por meio do ambiente construído, significados que estão engendrados por um processo de democratização do ensino.

Este Curso representa para os alunos, professores e funcionários envolvidos, uma busca por autonomia na construção dos significados, na qual os indivíduos buscam refúgio e solidariedade, sendo desta forma uma alternativa para a construção de identidades mais autônomas e produtoras de significações, valores e conhecimento.

É importante ressaltar que neste artigo fizemos um recorte de estudo a respeito de um dos aspectos formadores da identidade. Esperamos que outros estudos enfoquem outras dimensões da identidade do aluno do curso de pedagogia a distância, pois este é um tema ainda pouco abordado. E estes estudos podem contribuir para uma renovação de nossa percepção sobre a instituição e os papéis de seus protagonistas.

É importante que fique claro que existe uma "identidade vinculada", e assim, a identidade do aluno está vinculada à instituição de ensino na qual estuda, de forma que:

...os indivíduos, mesmo nas passagens e trânsito entre domínios e experiências mais diferenciadas, mantêm, em geral, uma identidade vinculada a grupos de referência e implementada através de mecanismos 
socializadores básicos contrastivos, como família, etnia, região, vizinhança, religião, etc. A tendência à fragmentação não anula totalmente certas âncoras fundamentais que podem ser acionadas em momentos estratégicos. Por outro lado, a fragmentação não deve ser entendida como um estraçalhamento literal do indivíduo psicológico. O trânsito entre os diferentes mundos, planos e províncias é possível, justamente, graças à natureza simbólica da construção social da realidade. (VELHO, 1994, p. 29)

Os alunos deste curso produzem sua identidade a partir de experiências que nós, a distância, nem podemos sonhar. $\mathrm{O}$ aluno não depende exclusivamente de sua relação com a instituição para construí-la, pois o processo de formação da identidade desse aluno nasce nas relações sociais e na sua construção imaginária do curso, de sua profissão, de seus professores, de sua turma, de seu grupo de estudo, de sua família e de sua prática docente na escola.

Em outras palavras, nossos alunos são pais e mães de família que se deparam com grandes demandas domésticas e rotineiras e com a formação de sua identidade em torno de seu papel de provedores. No início do curso eles tinham dificuldade em se permitir tempo para seu próprio desenvolvimento intelectual, a não ser que isto estivesse diretamente ligado ao aumento de sua capacidade de ganho e de competência no trabalho. Com o desenvolvimento do curso, sua busca pelo conhecimento é mais abrangente, ganhando significado em si mesmo.

A partir de algumas leituras sobre a área de andragogia ${ }^{3}$ e da educação de jovens e adultos podemos levantar algumas considerações a respeito dos alunos deste curso. Em sua maioria são pessoas adultas que trabalham, sua renda é média baixa, são pais e mães de família; possuem responsabilidades estendidas à família, igreja, comunidade; pararam de estudar já há algum tempo, sofrem de ansiedade em relação à retomada de seus estudos; por seu contexto de vida e trabalho voltadas para a subsistência tendem a ser pessoas pragmáticas; podem ter rejeição inconsciente a certas leituras que pareçam sem aplicação em seu cotidiano, pois possuem uma riqueza grande de conhecimentos baseados nas experiências como docente; têm cultura heterogênea,

3 Andragogia - A partir de 1970, Malcom Knowles trouxe à tona as idéias plantadas por Linderman. Publicou várias obras, entre elas The adult learner: a neglected species (1973), introduzindo e definindo o termo Andragogia: a arte e ciência de orientar adultos a aprender. Daí em diante, muitos educadores passaram a se dedicar ao tema, surgindo ampla literatura sobre o assunto. 
mas irão estudar com material didático igual; possuem reações e hábitos motivacionais diversos; eles consideram desmotivador quando ficam por muito tempo estudando o material e dialogando consigo mesmos e por isso se organizam em grupos de estudo que reconstituem o ambiente de debate e suporte encontrado em sala de aula; são pessoas que estão determinadas a concluir o curso.

Estas características do aluno da graduação a distância mostram o quanto ele é diferente do aluno da modalidade presencial e que suas necessidades e especificidades enquanto aluno deveriam ser investigadas de forma mais ampla. Este apenas pretende iniciar a discussão desta modalidade que tanto inova o cenário educacional brasileiro, quanto renova e enriquece nosso entendimento das práticas e relações construídas na modalidade presencial. $\mathrm{O}$ objetivo, ao iniciarmos esta análise, é despertar o interesse do leitor para pesquisas mais aprofundadas que tragam à tona tanto os aspectos positivos como negativos desta nova modalidade educacional.

\section{Considerações finais}

Este artigo não representa a visão dos alunos a respeito deles mesmos, a respeito do curso ou da própria universidade. Ele se volta para o desenvolvimento de algumas reflexões que julgamos necessárias que sejam compartilhadas com os colegas e alunos de nossa comunidade acadêmica, em um momento que estamos construindo a experiência e a prática desta universidade. Devemos discutir estas questões para que, apesar de todas as diferenças, sejam elas teóricas, ideológicas, políticas ou partidárias, possamos construir e reconhecer valores em comum e desenvolver um projeto comum de democratização do saber e dos valores fundamentais para uma universidade integrada com as necessidades sociais.

A regulamentação da EAD na universidade deve ser pensada por todos, mas deve ser pensada e representada principalmente pelos alunos, professores e funcionários do curso de pedagogia na modalidade a distância para que esta experiência contribua na regulamentação dos próximos cursos e o legitime dentro da instituição.

Nesta experiência podemos perceber que a identidade que os alunos constroem sobre si mesmos envolve a comunidade acadêmica que iniciou o 
projeto. Principalmente seus professores, pois estes vêm construindo o sentido de sua prática. Esta não contribui somente para a formação da identidade dos alunos, que está se modificando, mas também dos próprios professores que estão integrados com os alunos e, desta forma, criam uma identidade coletiva.

A base desta união e, conseqüentemente, desta identidade, não é o fato desta modalidade ser diferente da modalidade presencial. São as inúmeras dificuldades para se consolidar o projeto. Os desafios de desenvolver um curso pioneiro, o compromisso com a qualidade do ensino e as barreiras encontradas pelo preconceito em relação à educação a distância unificaram os professores, os alunos e as comunidades locais em um mesmo objetivo: o desejo de transformar o curso em realidade. Eles não se identificam entre si por se diferenciarem da modalidade presencial, mas por meio das relações construídas em um cotidiano desafiante. Desafios que contribuem para uma prática pedagógica transformadora.

A resistência institucional em relação à educação a distância, sem uma discussão prévia que englobe os diversos fatores que envolvem o curso, pode resultar em uma dissensão entre os protagonistas do curso de graduação a distância e aqueles que não desejam a legitimação do mesmo por visões préestabelecidas.

Por isso, o estudo mais detalhado de todo o processo de transformação destes alunos e do crescimento do curso enquanto ambiente de estudos e pesquisa precisa ser freqüentemente abordado por todos aqueles que constroem juntos este projeto e deveria se estender aos demais em um processo de reconhecimento do novo em uma universidade em constante transformação.

Este parece ser um processo de assimilação da modalidade a distância, não só para os professores, mas também para os alunos do curso presencial. Assim como é um processo de assimilação da cultura acadêmica pelos os alunos da modalidade a distância.

O sentido dado para o curso nesta universidade está se modificando, se transformando a cada experiência. A gama de possibilidades é muito ampla pois há uma liberdade muito maior para a expressão e a criatividade nas quais está se desenhando uma nova concepção de educação, em que o desejo de aprender é maior do que o desejo de saber. A dimensão desta expansão pode ser percebida pelas mudanças em atitudes, em questionamentos e, principalmente, nas relações sociais. E são estas experiências que devem ser registradas para que os futuros alunos percorram caminhos novos, mais estáveis e consolidados em discussões, práticas e pesquisas. Esta consolidação não é somente uma construção dos participantes diretos neste projeto, mas de todos aqueles 
que se voltam para analisar, pensar, discutir e avaliar o processo do curso. Afinal, é importante que a identidade que está sendo construída não seja reconhecida como oposta à identidade dos alunos do curso presencial, pois isto pode enfatizar diferenças irrelevantes, desconsiderando as semelhanças que unem todo projeto educacional: o desenvolvimento do conhecimento na pesquisa, no ensino e na extensão. Precisamos juntos pensar um projeto de universidade que recrie novos significados para a educação.

\section{REFERÊNCIAS}

CASTELLS, M. O poder da identidade. 2. ed. São Paulo: Paz e Terra, 2000.

CASTORIADIS, C. A instituição imaginária da sociedade. Tradução: Guy Reynaud. 5. ed. Rio de Janeiro: Paz e Terra, 2000.

PRETI, O. Autonomia do aprendiz na educação a distância: significados e dimensões. Educação a distância: construindo significados. Cuiabá: NEAD/IE - UFMT, Brasília: Plano, 2000.

VELHO, G. Projeto e metamorfose. Antropologia das sociedades complexas. Rio de Janeiro: Zahar, 1994.

Texto recebido em 20 jan. 2003 Texto aprovado em 20 de mar. 2003 